\title{
Monitoring of Electric Current During Electrokinetic Stabilisation Test for Soft Clay using EKG Electrode
}

\author{
Saiful Azhar Ahmad Tajudin ${ }^{1, a}{ }^{*}$, Ian Jefferson ${ }^{2, b}$, Aziman Madun $^{3}$, \\ Mohd Hazreek Zainal Abidin ${ }^{4}$, Mohamad Faizal Tajul Baharuddin ${ }^{5}$, \\ Mohd Adib Mohammad Razi ${ }^{6}$ \\ 1,3,4,5,6 Faculty of Civil and Environmental Engineering, University Tun Hussein Onn Malaysia, \\ Malaysia \\ ${ }^{2}$ School of Civil Engineering, University of Birmingham,UK \\ asaifulaz@uthm.edu.my*, bi.jefferson@bham.ac.uk
}

Keywords: Electrokinetic Stabilisation, Soft Clay, Electrokinetic Geosynthetic, Electroosmosis.

\begin{abstract}
Electrokinetic Stabilisation (EKS) method has the potential to overcome problems on highly compressible clay. This study presents the monitoring results from an experimental study of EKS on soft clay soil. Inactive kaolinite clay, inert electrode and distilled water (DW) were used as a pure system mechanism before any chemical stabilisers are utilised for stabilisation. Therefore, this monitoring data will provide a baseline study to improve efficiency of the EKS approach for ground improvement application. An inert electrode of Electrokinetic Geosythentic (EKG) developed at the Newcastle University was utilised to apply a constant voltage gradient of $50 \mathrm{~V} / \mathrm{m}$ across a soil sample of $400 \mathrm{~mm}$ length. The distilled waters were used at the pore electrolyte fluid compartments and supplied under zero hydraulic gradient conditions for periods of 3,7 and 14 days. Throughout, monitoring data of electric current for all treatments were measured. Results showed that the electric current trend in this pure system was attributed to the electrochemical effects in the clay-water electrolyte system.
\end{abstract}

\section{Introduction}

The application of deep chemical ground improvement using the Electrokinetic Stabilisation (EKS) method has the potential to overcome problems on highly compressible soft soil $[1,2,3,4]$. This technique also has the potential to be applied to treat contaminated soils for geoenvironmental application [5,6]. Electrokinetic stabilisation of clay soils using calcium-based stabilisers [2,3], lime [7] and other types of stabilizers [8,9] have been used widely for geotechnical application. In some cases, these methods are suitable to stabilise soil under existing structure $[1,8]$. Therefore, it is expected that chemical improvement of soils in situ using electrokinetic stabilisation will play a very important role in the future not only as an alternative method for problematic soil whether under existing foundation or as part of a new development.

Current research [1] conducted at the University of Birmingham, successfully proved the concepts and established the practical possibilities of improving the classical chemical modification and stabilisation reactions in situ. At the same time this work overcomes problems caused by electrode degradation [10]. However, further experiment need to be performed to assess EKS performance when appropriate selected chemical stabilisers are added into the clay soil. These chemical stabilisers are migrated across the soil sample by electrical gradient depend on their charge of ions towards the opposite charge of electrodes. For that reason, the present study developed a new approach to treat soft clay soils in order to modify and improve their properties. By providing a better understanding of the 'pure' relatively inert system, which has no chemicals introduced, this hopefully will provide a baseline study to improve efficiency of the EKS approach when applied to soft compressible soils. Thus this technique has potential to enhance key strength and stiffness gain under foundations to ensure this is controlled in the most efficient way. 


\section{Materials and Methods}

Development of Experimental Apparatus An experimental programme was conducted to assess the efficiency of EKS when applied to soft clay soil. The EKS model apparatus consisted of tank made of non-conductive material (PVC-U sheet) to prevent short circuiting. The PVC-U sheet is 12 $\mathrm{mm}$ thick with internal dimensions of $450 \times 220 \times 550 \mathrm{~mm}$. The tank consists of main compartment of internal dimension $370 \times 220 \times 550 \mathrm{~mm}$ to locate soil samples for treatment and two small compartments that had internal dimension of $40 \times 220 \times 550 \mathrm{~mm}$ to supply the distilled waters (DW) into the soil. A schematic diagram of the EKS testing model is shown in Fig. 1.

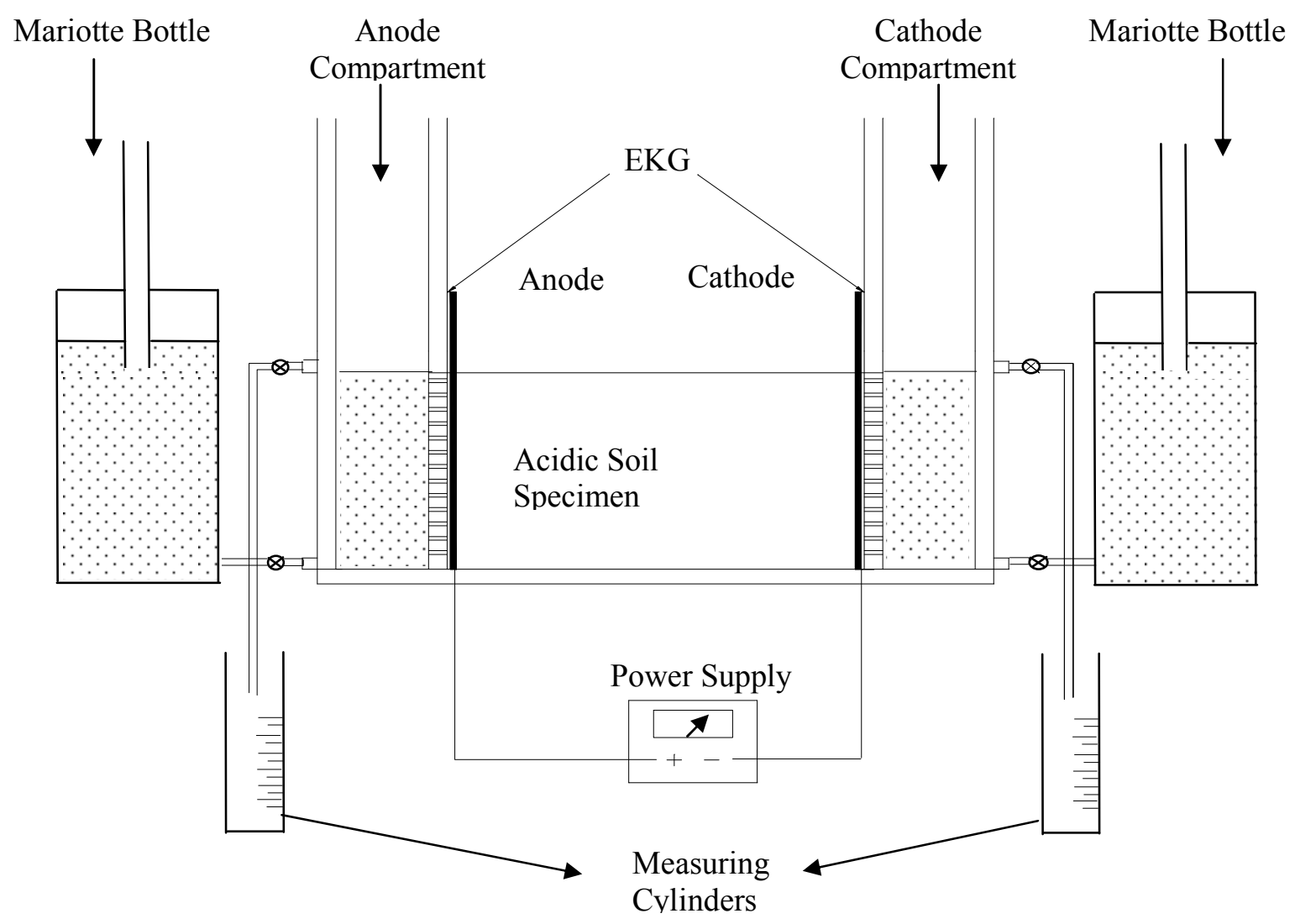

Fig. 1 Schematic Diagram of EKS Testing Model

A DC power supply obtained by Thurlby Thandar Instruments (model TS3022S) was used to supply power to the electrodes. A constant voltage gradient of $50 \mathrm{~V} / \mathrm{m}$ was used for all electrokinetic treatment for 3, 7 and 14 days so that the effects of electric current with time could be assessed.

Soil Specimen Preparation A consistent method of soil specimen preparation was employed throughout this work for all treatment periods. The slurry sample was prepared by mixing the clay soils with deionised water to achieved $90 \%$ water content. The water content of slurry was chosen based on 1.5 time liquid limit (LL) to produce homogeneous sample. Approximately, $10.66 \mathrm{~kg}$ of deionised water was poured into the mixer bowl and then $11.84 \mathrm{~kg}$ of dry English China clay was gradually added to ensure consistency of mixing. The slurry sample was then mixed using Hobart mechanical mixer and blended thoroughly for 30 minutes. Two mixtures of slurry samples need to be filled in the tank with total of amount of soil and water was 23.68 and $21.32 \mathrm{~kg}$, respectively, achieving a water content of $51 \%$ for all test samples.

The initial height of the slurry is $386 \mathrm{~mm}$ for all tests samples. The load was applied to consolidate the slurry sample until it reached final height of about $271 \mathrm{~mm}$ using hydraulic jack to achieve moisture content of $51 \%$. The first consolidation pressure was set at approximately $10 \mathrm{kPa}$ 
for about 24 hours to prevent soil particle migration via the drainage. The subsequent surcharge pressures were gradually increased in four increments over a 4 days period until final height was reached. After consolidation thin solid plastic walls were removed at both end of soil compartment and the gaps left were then inserted with the Electrokinetic Geosythentic (EKG) electrodes. The soil samples were reconsolidated under the same loading as the last consolidation $(67.9 \mathrm{kPa})$ for about 24 hours before the loading was released upon EKS testing. Subsequently, the electric current were turned and monitored throughout the test durations. This was performed to make sure a good contact between soils and electrodes. Physical and chemical properties of the treated soil were carried out along the soil profiles that were divided into eight sections from anode to cathode.

\section{Results and Discussions}

Basic Properties of Soil The basic physical and chemical properties of clay soil were investigated first through laboratory programme in accordance to BS 1377: 1990 as shown in Table 1. Then, a laboratory investigation of EKS approach was carried out which was developed at University of Birmingham. Commercially available EKG electrodes were used to prevent the degradation of electrode especially at the anode that requires replacement during the treatment. In order to avoid the complexity of the system with different clay minerals and chemical changes that associate with coupled flows, $\mathrm{pH}$ gradient and electrolysis and redox reactions, a relatively 'pure' and inert form of kaolin (English China Clay) was used in this study supplied by WBB Devon Clays. In addition, kaolin clay was selected in this study due to its low activity, low adsorptive capacity and high electro-osmotic transport efficiency compared with other clays.

Table 1: Properties of English China Clay

\begin{tabular}{ll}
\hline Particle Size Distribution : & \\
Silt & $49 \%$ \\
Clay & $51 \%$
\end{tabular}

\begin{tabular}{ll}
\hline Atterberg Limit : & \\
Liquid Limit & $60 \%$ \\
Plastic Limit & $34 \%$
\end{tabular}

\begin{tabular}{lc}
\hline Permeability : & \\
Falling Head Test & $2.2 \times 10^{-8} \mathrm{~m} / \mathrm{s}$ \\
Oedometer Test & $2.6 \times 10^{-10} \mathrm{~m} / \mathrm{s}$
\end{tabular}

\begin{tabular}{lc}
\hline Average specific gravity $\left(\mathbf{G}_{\mathbf{s}}\right):$ & 2.63 \\
\hline Compression index $\left(\mathbf{C}_{\mathbf{c}}\right):$ & 0.365 \\
\hline pH value : & 5.1 \\
\hline Conductivity : & $19.6 \mu \mathrm{S} / \mathrm{cm}$ \\
\hline Surface Area : & $8-10 \mathrm{~m}^{2} / \mathrm{gm}$ \\
\hline
\end{tabular}

Monitoring Data Fig. 2 shows monitoring of electric current for 3, 7 and 14 days of DW-DW system. It was observed that electric current of these 3 different periods shows similar trend except for 14 days treatment period which has lower value of about $9 \mathrm{~mA}$ at the beginning of test, compared with 3 days and 7 days treatment periods which has value of 12 and $13 \mathrm{~mA}$, respectively. 


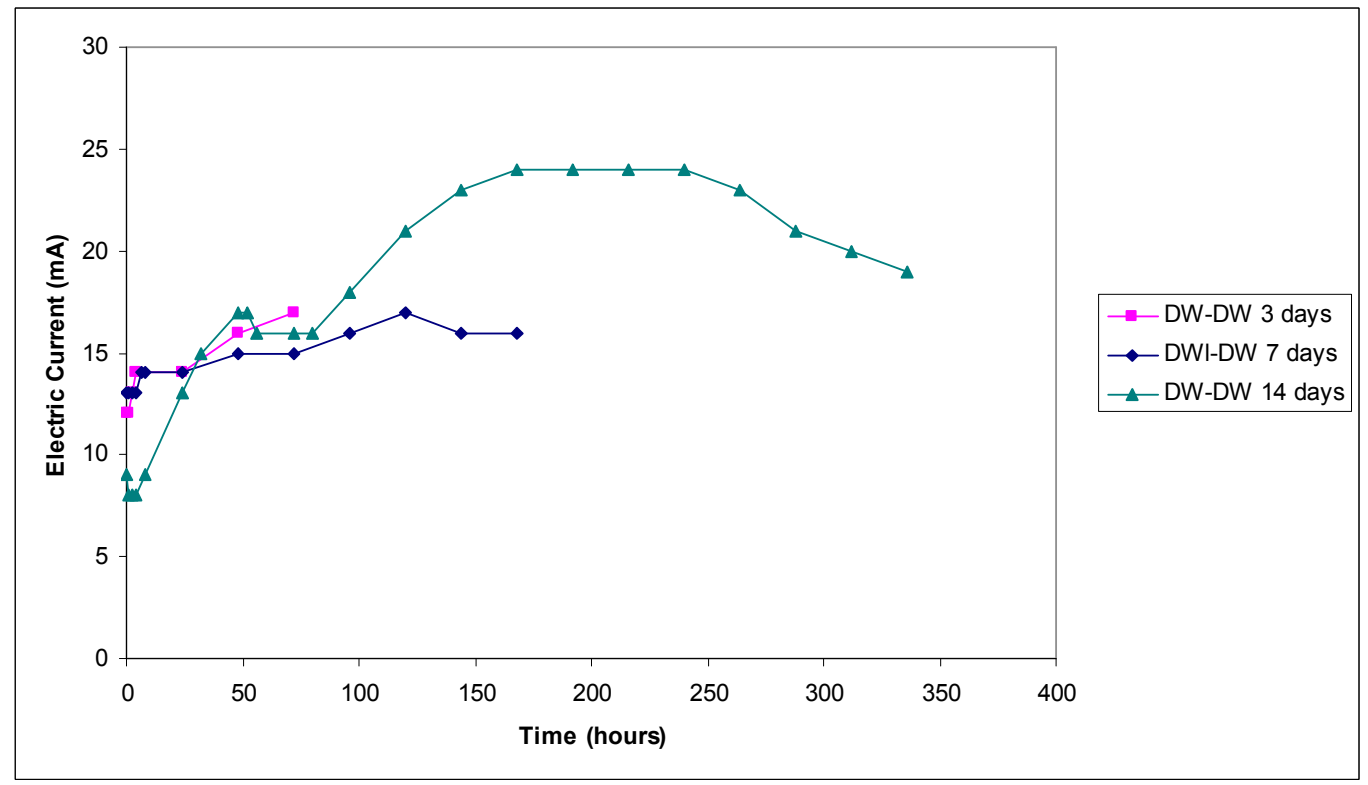

Fig. 2 Electric Current of DW-DW system with time.

After 24 hours duration of EKS testing, the electric current values for 3, 7 and 14 days treatment period were reached at about 13 to $14 \mathrm{~mA}$. The value of record current maintained these values, with similarly seen until 96 hours with both 7 days and 14 days tests. However, after this time for the 14 days test current rose, peaking at around 170 hours at $24 \mathrm{~mA}$ before dropping over the last 4 days (96 hours) to a value of $19 \mathrm{~mA}$. The electric current trend in this pure system was attributed to the electrochemical effects in the clay-water electrolyte system which varied across the samples with time, thus affected the current profiles during tests.

The electric current variations with treatment time for the same type of electrode are comparable with Liaki [10] who reported that the current initially increase at about $14 \mathrm{~mA}$, while it then drops within the first 100 hours of treatment, as resistant of the materials increases and the voltage was set at the constant level. However, it was observed a large variation especially at the beginning which reported by Liaki [10] with different treatment time. This was due to the soil electrode contact which varied upon insertion of electrode during sample preparation which causes large variation especially at the beginning. Therefore, the improvement of the procedures and design configuration made for the current research has overcome the problem related to the soil-electrode interfaces. It should be noted that after consolidation thin solid plastic walls were removed at both end of soil compartment and the gaps left were then inserted with the EKG electrodes. In order to make sure a good contact between soils and electrodes, the soil samples were subjected to load under the same loading of the last consolidation for about 24 hours before electric current were turned on.

\section{Conclusion}

The results presented and discussed in this study are comparable with previous study performed by Liaki [10]. However, the improved version of the procedures and design considerations have been made in this study to solve the problem faced by many researchers $[7,8,9,10]$ and to achieve the objectives of this study before any chemical stabilisers are introduced into the system. The results from monitoring data showed that there are several important mechanisms relating to the electrochemical effects and these can be drawn from this study using a pure system. The electric current profiles are influenced by the ionic concentration of the pore fluid within the soil matrices. Therefore, the addition of distilled water at both anolyte and catholyte compartments had caused increase of the electric current at the beginning of the test, but then decreased with treatment time indicating that a high resistivity zone forms due to precipitation of metal hydroxide at the vicinity of the cathode from the clay mineral itself and pore fluid. This phenomenon has also caused the fluid flow to stop, thus decreasing the electric current across the soil sample. 


\section{Acknowledgements}

The authors would like to thank the Ministry of Higher Education and Universiti Tun Hussein Onn, Malaysia for supporting this research under Fundamental Research Grant Scheme (FRGS) Vot. 1455.

\section{References}

[1] S.A. Ahmad Tajudin: Electrokinetic Stabilisation of Soft Clay, School of Civil Engineering, University of Birmingham, UK, (2012).

[2] N.S. Nordin, S.A. Ahmad Tajudin, A. Abdul Kadir: Physical properties of treated soft clay by using electrokinetic stabilisation method, Soft Soil Engineering International Conference, (2013).

[3] N.S. Nordin, S.A. Ahmad Tajudin, A. Abdul Kadir: Stabilisation of soft soil using electrokinetic stabilisation method, International Journal of Zero Waste Generation (2013).

[4] M. Nasim, O. Erwin, C. Gary: A review of electrokinetic treatment technique for improving the engineering characteristic of low permeable problematic soil, Int. J. of GEOMATE, Vol. 2. No. 2. 2011, pp.266-272.

[5] S. Glendinning, J. Lamont-Black, C.J.F.P. Jones, Treatment of sewage sludge using electrokinetic geosynthetics, J. Hazard. Mater. A 139, (2007) p. 491-499.

[6] A.T. Yeung: Contaminant Extractability by Electrokinetics, Environmental Engineering Science, vol. 23 (1), (2006) p. $202-224$.

[7] J.E. Barker, C.D.F. Rogers, D.I. Bordman, J. Peterson: Electrokinetic stabilisation: An overview and case study, Ground Improvement, (2004) p. 47-58.

[8] A.N. Alshawabkeh, T.C. Sheahan,: Soft soil stabilisation by ionic injection under electric fields, Ground Improvement vol. 7, (2003) p. 177-185.

[9] P. Asavadorndeja, U. Glawe: Electrokinetic strengthening of soft clay using the anode depolarization method, Bull. Eng. Environ., vol.64, (2005) p. 237-245.

[10] C. Liaki, C.D.F. Rogers, D.I. Boardman: Physico-chemical effects on clay due to electromigration using stainless steel electrodes, J Appl Electrochem, (2010) p. 1225-1237. 